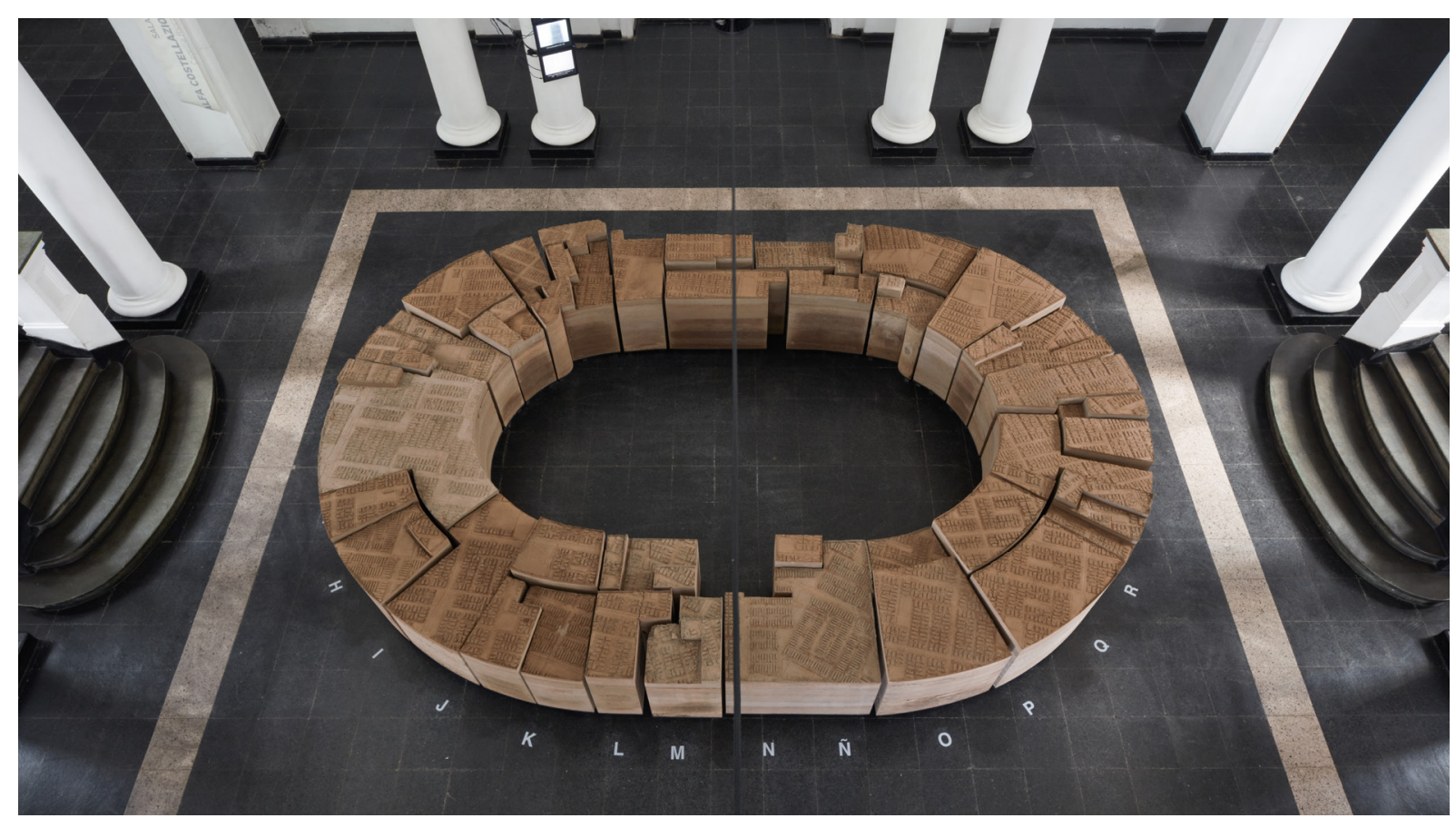




\section{Estadio y Museo: Una cartografía de impulsos narrativos Alejandra Celedón}

Construir un Estadio para un Museo fue la operación detrás del "Stadium", el Pabellón de Chile en la 16ª Bienal de Venecia de 2018. La exhibición recuperó un evento olvidado de la historia local reciente donde, durante la dictadura de Pinochet, se otorgaron 37.000 títulos de propiedad a pobladores de Santiago en el Estadio Nacional de Chile. Para el evento en 1979 se redibujó una planta del edificio que en vez de graderías trazó polígonos con el nombre de más de 60 poblaciones de la periferia de Santiago de donde provenían los convocados ese día. El dibujo, punto de partida de "Stadium", reúne en un mismo esfuerzo un impulso cartográfico y uno narrativo. Stadium discute sus premisas desde una segunda adaptación del pabellón, donde se reconstruye el estadio para el Museo de Arte Contemporáneo de Santiago en 2019. La muestra, al igual que el evento del pasado, transporta la ciudad a un edificio, $y$ hace visible la periferia en el centro. Así, el Arsenal Veneciano y el Museo de Arte Contemporáneo de Santiago hacen eco de su contenido y abren nuevas reflexiones disciplinares a partir de las operaciones que involucran: en ellos un edificio es comprimido dentro de otro edificio, o incluso una ciudad dentro de otra. "Stadium" retoma la premisa de Rossi sobre la Arquitectura para el Museo para plantear su potencial para abrir debates críticos sobre la arquitectura y sus prácticas.

\section{PALABRAS CLAVE}

Estadio, museo, vivienda social, Bienal de Venecia, narrativa, cartografía

\section{KEYWORDS}

Stadium, Museum, Social Housing, Venice Bienal, Narrative, Cartography

\section{La obstinación, como diría Aldo Rossi, es el primer} anticipo de teoría en el arte y en la arquitectura. Refleja cómo ciertos problemas elegidos para ser desarrollados siempre regresan, independientemente del material que tengamos al frente. Detrás de la muestra "Stadium", el pabellón que representó a Chile en la 16ª Bienal de Arquitectura de Venecia en 2018, hubo una obstinación con el dibujo como lugar de conocimiento, con el dibujo (y el redibujo) de la planta de arquitectura como un instrumento activo que administra vidas y territorios. Una

\begin{abstract}
Alejandra Celedón
Arquitecta, Universidad de Chile, 2003. MSc Advance Architectural Studies, the Bartlett, UCL (Londres, Inglaterra), 2007. $\mathrm{PhD}$ Architectural Association (Londres, Inglaterra), 2014. Curadora de Stadium, $\mathrm{Pa}$ bellón de Chile en la $16^{\mathrm{a}}$ Bienal de Arquitectura de Venecia. Sus últimas publicaciones incluyen Stadium: A Building to Render the Image of a City (2018) y "La Biblioteca Nacional de Chile, cien años tarde, cien años después" (ARQ). Ha dictado conferencias en Royal College of Arts, The Architectural Association y The Berlage y seminarios de postgrado en Universidad Torcuato di Tella (2017) y Universidad de Navarra (2018). Actualmente se desempeña como docente e investigadora en la Pontificia Universidad Católica de Chile.
\end{abstract}

Fig. 01

Stadium en el Museo de Arte Contemporáneo, Santiago de Chile, Mayo-Julio 2019.

Fuente: (c) Felipe Fontecilla. 
Fig. 02

Planta del Estadio Nacional de Chile preparada por el Ministerio de Vivienda y Urbanismo para el acto de firma de títulos de dominio.

Fuente: Biblioteca Nacional de Chile. persistencia en pensar los edificios como proyectos políticos y sociales, la arquitectura como una misma cosa con la ciudad, con lo público y su historia. Una obstinación con los objetos y su capacidad para desarrollar historias, y con el museo como el lugar donde desplegarlas. Un año más tarde, "Stadium" fue adaptada para ser expuesta en el Museo de Arte Contemporáneo de Santiago de Chile. En ambos casos, la operación principal fue comprimir un edificio enorme, el Estadio Nacional, en un pequeño espacio de exposición: la Sala del'lsolloto del Arsenale primero, y el hall central del Museo después. La exposición no sólo instaló un estadio a escala 'dentro' de un espacio expositivo, sino que -siguiendo a Cézanne, quien 'pintaba sólo para los museos'- la muestra concibió y construyó un estadio 'para' un museo.

Como parte de un trabajo de investigación más extenso sobre retóricas y políticas de vivienda durante la década de los 80 en Santiago de Chile', y a raíz de conversaciones con pobladoras sobre el origen de sus sitios y casas, aparece de manos de una de ellas un dibujo. Una planta sin escala del Estadio Nacional de Chile que, en lugar de graderías y asientos, encerraba (en más de 60 polígonos dibujados) los nombres de diferentes poblaciones y villas de las 17 comunas que en ese entonces formaban la periferia del Gran Santiago. 29 de septiembre de 1979 registraba el dibujo (de aproximadamente $30 \mathrm{~cm}$ de alto y $55 \mathrm{~cm}$ de ancho), con un pliegue al medio y marcas de corchetes, como si hubiera sido parte de un fascículo mayor. Una imagen -un objeto, lo suficientemente intrigante: una planta para un evento que superponía un impulso cartográfico y uno narrativo en

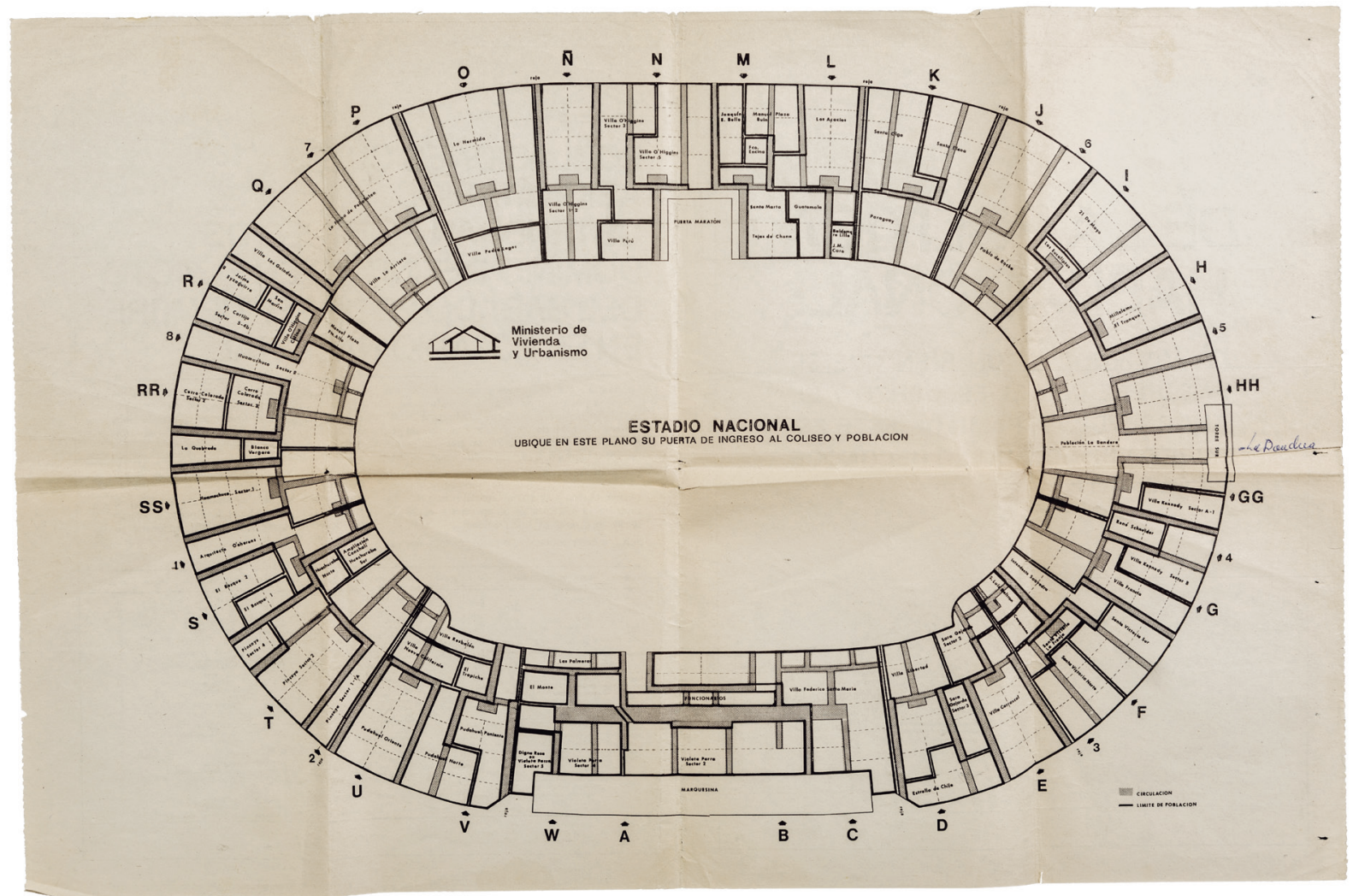


un mismo gesto. El impulso narrativo estaba dado por la referencia del dibujo a un episodio del pasado: la firma de títulos de propiedad de alrededor de 37.000 pobladores de la periferia de Santiago. La planta fue preparada para este propósito: reunir poblaciones distantes dentro de la forma ovalada del edificio del estadio, en un esfuerzo sinóptico y panorámico (fig. 02).

La exposición se desarrolla a partir del dibujo una historia relativamente desconocida del estadio, o más bien, en palabras de Anthony Vidler, a partir de las historias que un monumento nunca revela por completo, sino que a veces incluso oculta ${ }^{2}$. Este evento, que tuvo lugar durante la dictadura militar de Augusto Pinochet, desencadenó una nueva política habitacional que transformaría la naturaleza de la vivienda social: de un derecho irrenunciable a una mercancía que puede comprarse e intercambiarse, sometida a la capacidad de ahorro de los potenciales propietarios. En adelante, sería el mercado (y no el Estado de bienestar) quien regularía la vivienda, desde el valor del suelo hasta su construcción real. El acontecimiento, en la primavera previa al cambio de década, también anunciaba la creación de un nuevo sujeto urbano: de poblador a propietario, y por la misma moneda, deudor. El estadio se llenó de personas provenientes de todas partes de la ciudad- o más bien, de la periferia obrera de Santiago. No fueron convocados para un concierto o un evento deportivo, sino para un operativo gubernamental de orden jurídico-administrativo y carácter masivo, destinado a procesar en un solo día miles de títulos de dominio. Lo que se cristalizó ese día, al otorgar instrumentos de deuda con coordenadas espaciales específicas, fue una planta para una ciudad que no tenía plan, reforzando la histórica segregación urbana de Santiago (fig. 03).

La ciudad privatizada se celebró paradójicamente en uno de los edificios más públicos de Santiago. Los compradores, que ya eran pobladores, desconocían el contrato que suscribían. La prensa oficialista anunciaba la entrega de 160.000 títulos de dominio a lo largo de todo el país en otros estadios y anfiteatros antes del cambio de década. Si se considera un promedio de 6 personas por cada título de dominio, esto comprometía en un mismo operativo a cerca de un millón de ciudadanos en un país de 11 millones de habitantes. Para alcanzar las cifras prometidas, los contratos fueron propuestos unilateralmente por el Ministerio de Vivienda y funcionaron como cuotas uniformes para los 37.000 sitios, independientemente de las historias y particularidades de cada caso. La eficiencia fue la retórica empleada para desconocer pagos anteriores, a riesgo de perder el sitio en caso de falta de pago de tres cuotas consecutivas. Si bien la retórica anunciaba la idea de propiedad como un valor sine qua non, la realidad fijaba los futuros deudores de sitios que ya estaban ocupados desde hacía una década o más. "Stadium" presenta la arquitectura de una paradoja, exponiendo a través de su libertad tipológica una tensión inherente con el neoliberalismo. Para el total de la década, entre 1983 y 1989, se emitieron finalmente 555.965 títulos de dominio en todo el país, que a través de una operación biopolítica terminaron impactando a cerca de 2,5 millones de personas. La propiedad de la vivienda estaba destinada a generar orgullo por el sistema y, en consecuencia, por el gobierno que lo había establecido. Denominado 'dividendo de propiedad o lealtad', éste "reforzaba el apoyo al régimen como una manera de fortalecer su legitimidad"3. El régimen supo capitalizar este sistema de valor de varias maneras. Los títulos se conferían con considerable fanfarria y ceremonia pública y fueron utilizados para impulsar su proyecto 
Fig. $\mathrm{O3}$

1. Conchali $11 \mathrm{~km}$ (58 stadium) 2. Ñuñoa 4,7 km (26 stadium) 3. Maipú 9 km ( 49 stadium) 4. Renca $13 \mathrm{~km}$ (70 stadium) 5. Quilicura $11 \mathrm{~km}$ (62 stadium) 6. Colina $41 \mathrm{~km}$ (221 stadium) 7. Pudahuel $17 \mathrm{~km}$ (91 stadium) 8. La Florida $9 \mathrm{~km}$ (50 stadium) 9. San Miguel $5 \mathrm{~km}$ (28 stadium) 10. La Cisterna $10 \mathrm{~km}$ (53 stadium) 11. La Granja 8 km ( 41 stadium) 12. Puente Alto $15 \mathrm{~km}$ ( 80 stadium) 13. Talagante $36 \mathrm{~km}$ (198 stadium) 14. Peñaflor $41 \mathrm{~km}$ (224 stadium) 15. El Monte $47 \mathrm{~km}$ (257 stadium) 16. San Bernardo $15 \mathrm{~km}$ (82 stadium) 17. Buin 32 km (175 stadium)

Fig. 04

Poblaciones:

1. Pincoya

2. Huechuraba Sur

3. El Bosque

4. Arquitecto $\mathrm{O}^{\prime} \mathrm{Herns}$

5. Huechuraba Norte

6. Ampliación Conchali

7. Villa lo Arrieta

8. La Faena de Peñalolen

9. Jaime Eyzaguirre

10. Villa los Guindos

11. Lo Hermida

12. Pedro Lagos

13. Villa Francia

14. Villa Robert Kennedy

15. Villa Rene Schneider

16. Huamachuco

17. Cerro Colorado

18. La Quebrada

19. Blanca Vergara

20. Cortijo

21. Villa O higgins

22. San Martin

23. La Victoria Sur

24. Pudahuel Oriente

25. Cauquenes

26. Federico Santa María

27. Violeta Parra

28. Villa Libertad

29. Estrella de Chile

30. Intendente Saavedra

31. San Luis Beltrán

32. Villa Carrascal

33. Sara Gajardo

34. Digna Rosa

35. Villa Resbalon

36. Villa Nueva California.

37. Villa Ohiggins.

38. Villa Perú.

39. Francisco Encina

40. Joaquin Edwards Bello.

41. Jose María Caro.

42. Guatemala.

43. Los Acadios.

44. Santa Elena.

45. Santa Olga.

46. Baldomero Lillo

47. Los Eucaliptus

48. Pablo de Rokha

49. La Bandera

50. 21 de Mayo

51. Paraguay

52. El Traque

53. Millalemu

54. Manuel Plaza

55. Las Palmeras

56. El Trapiche

57. El Monte 2

58. Tejas de Chena

59. Santa Marta

60. Manuel Plaza
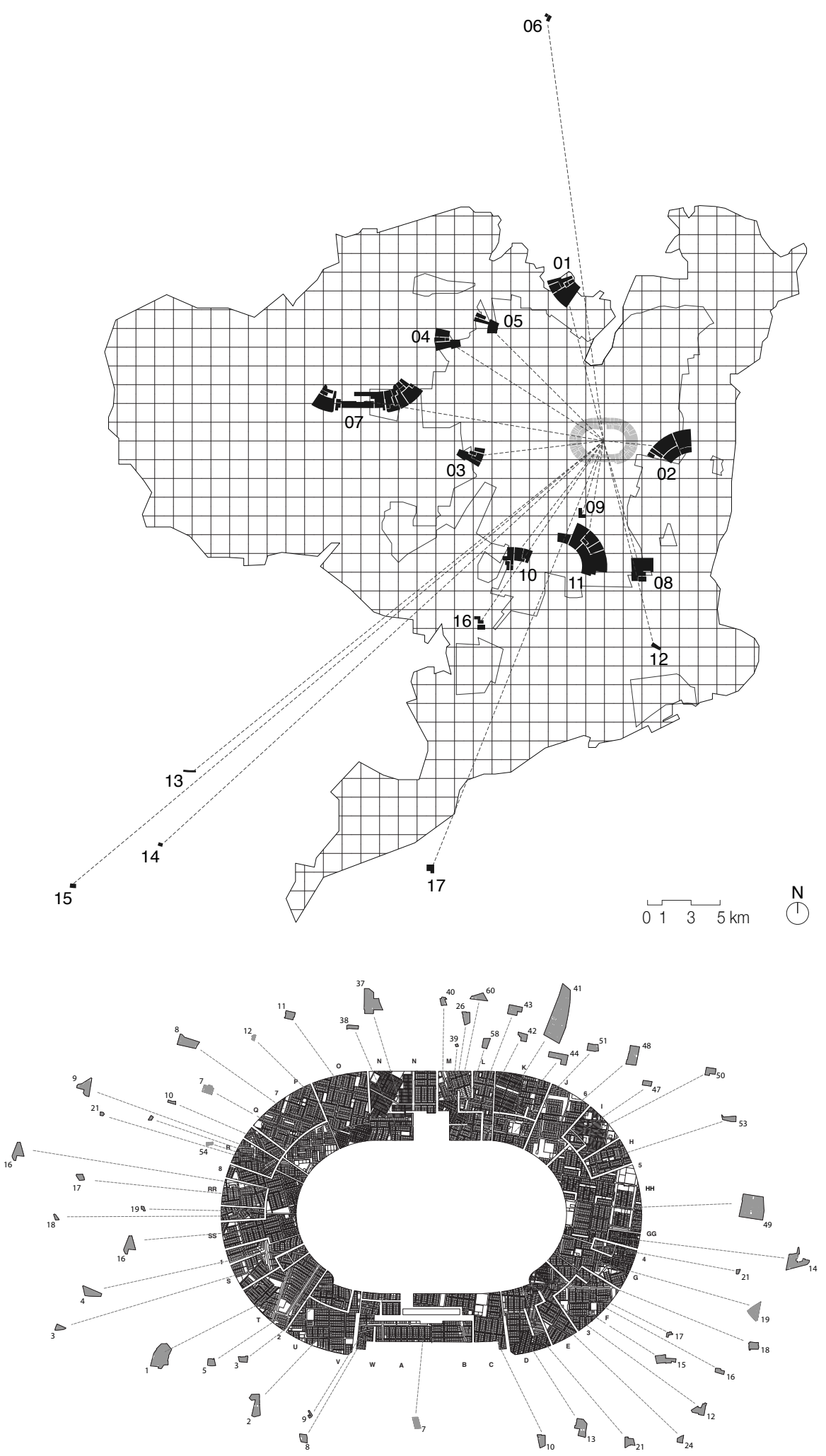
político. Lotes de $9 \times 18$ metros habían ya sido entregados en lo que se denominó la "Operación Sitio", una iniciativa nacional para la autoconstrucción de viviendas de la década del 60 que respondía a la grave crisis habitacional en Chile otorgando a las personas un terreno trazado con tiza en el suelo como un intento de enfrentar la proliferación de ocupaciones ilegales. La mayoría de las personas reunidas en el estadio eran sus beneficiarios.

A partir de la planta original elaborada para el evento, y que circuló en la prensa oficial de la época, el equipo curatorial redibujó un nuevo diagrama. Compuesto por el tejido urbano proveniente de la periferia de la ciudad, la planta del estadio se convierte en un palimpsesto de islas disgregadas. El redibujo de la planta hace visible una ciudad marginada en sus bordes, una ciudad de fragmentos desconectados que, por un día, se condensan en la figura panóptica del edificio (fig. 04). En Venecia, en mayo de 2018, la primera versión de la estrategia curatorial consistió en construir un estadio hecho de tierra en una ciudad fundada sobre agua. Cada una de las poblaciones y villas fue extruida a alturas variables (entre 10 y 13 capas de tierra apisonada), donde la última capa es estampada la trama urbana del fragmento de ciudad que individualiza. $Y$ pese a que estos tejidos urbanos son distintos, comparten una característica común: los lotes de $9 \times 18$ metros se repiten como un timbre estampado. El modelo a escala 1:40, de 7 por 5 metros y aproximadamente un metro de altura, busca abandonar su condición normalizada de maqueta de una realidad a la cual representa, para convertirse en un objeto autónomo - pieza de museo, instalación y obra de arte: un Estadio para un Arsenal (fig. 05).
Fig. 03

Planta de Santiago mostrando las ubicaciones de las poblaciones presentes en el Estadio el 29 de septiembre de 1979. Fuente: (c) Equipo curatorial.

\section{Fig. 04}

Planta del Estadio explotada en referencia a la forma de las poblaciones reales a las que refiere.

Fuente: (c) Equipo curatorial.

Fig. 05

Stadium, Un edificio que visualiza la imagen de una ciudad. Pabellón de Chile en la 16va Bienal de Arquitectura de Venecia.

Fuente: (c) Gonzalo Puga.

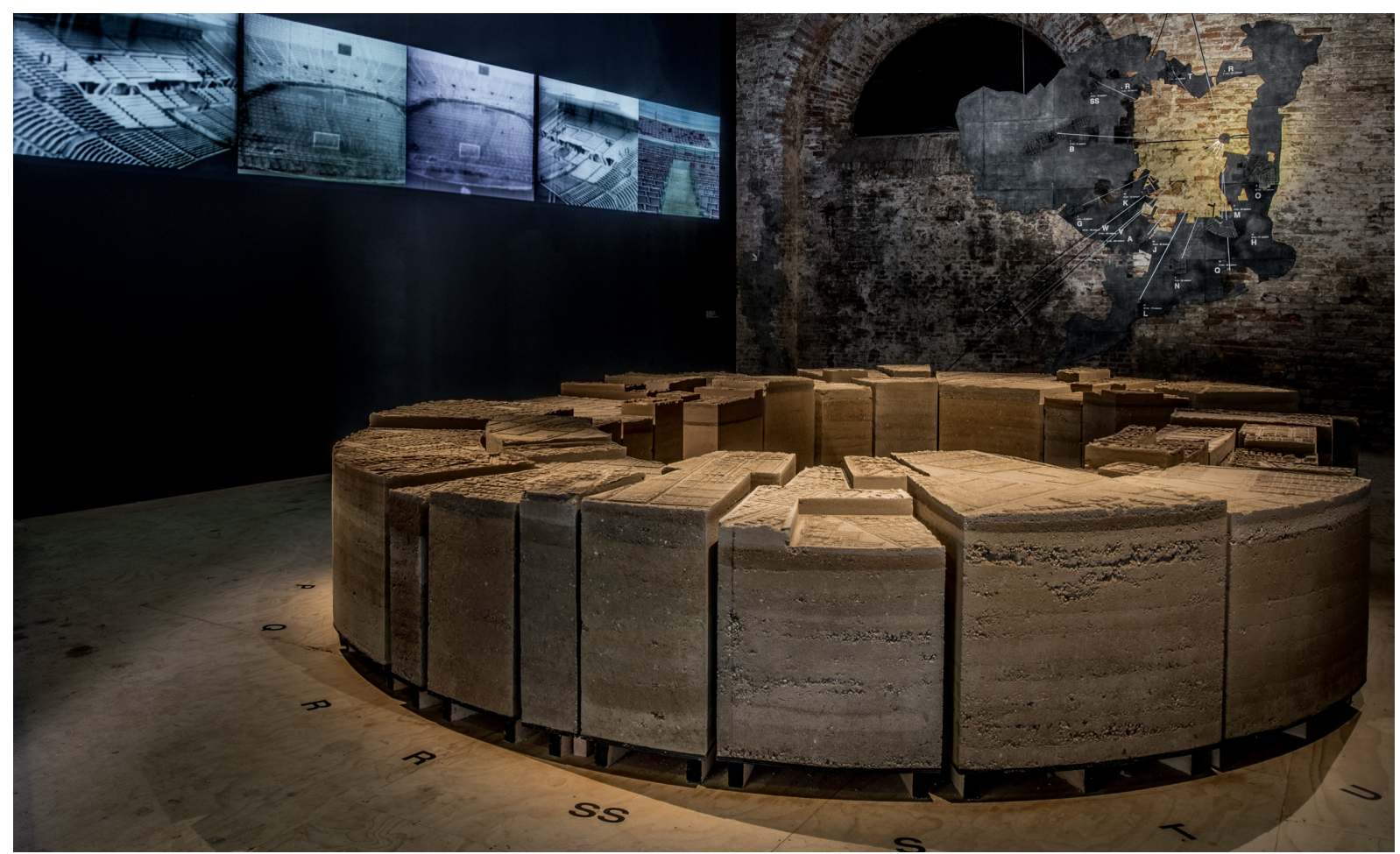


Fig. 06

Fábrica detrás de la exhibición para construir in situ el Estadio en el Arsenal de Venecia.

Fuente: (c) Gonzalo Puga.
No sólo la historia del Estadio es comprimida al interior de un antiguo depósito de armas y materiales de guerra, sino que también se comprime un fragmento de la historia de la ciudad de Santiago en la ciudad de Venecia. Este pasado particular hace referencia a un evento histórico que durante un breve instante permitió visualizar una ciudad completa contenida dentro de un edificio. La palabra arsenal deriva del árabe 'dar as-sina'ah': 'dar', que puede traducirse como 'casa' y 'sina'ah', que significa 'fábrica'. El de Venecia fue la fábrica donde se construían, reparaban y almacenaban barcos, municiones y armas. Las viviendas de los trabajadores se extendían fuera de sus muros. El astillero fue clave en la construcción del poder naval veneciano y la defensa de la ciudad. Como registran los versos de Dante, el Arsenal es tan antiguo como la Divina Comedia. Un estadio de mediados del siglo XX se erige dentro de una construcción de principios del siglo XII todavía en pie. Tal compresión temporal y geográfica - de un edificio dentro de un edificio (como destacó Anthony Vidler), y de una ciudad dentro de la ciudad (como prefirió Alejandro Zambra)- sólo es posible a través de una arquitectura para el museo 4 (fig. 06).

Cuando abrió sus puertas en 1938, el Estadio Nacional fue el edificio más grande de Santiago, herramienta y símbolo de modernización, que promovía el deporte como modelo de un cuerpo ciudadano ideal. Tres años más tarde sería el dispositivo para otro tipo de formación, en la administración masiva de la Primera Comunión a cien mil niños católicos. Sería también una tribuna política recurrente, con un sinnúmero de presidentes de la República que utilizaron el Estadio como plataforma para dirigirse al país, desde su construcción hasta el quiebre

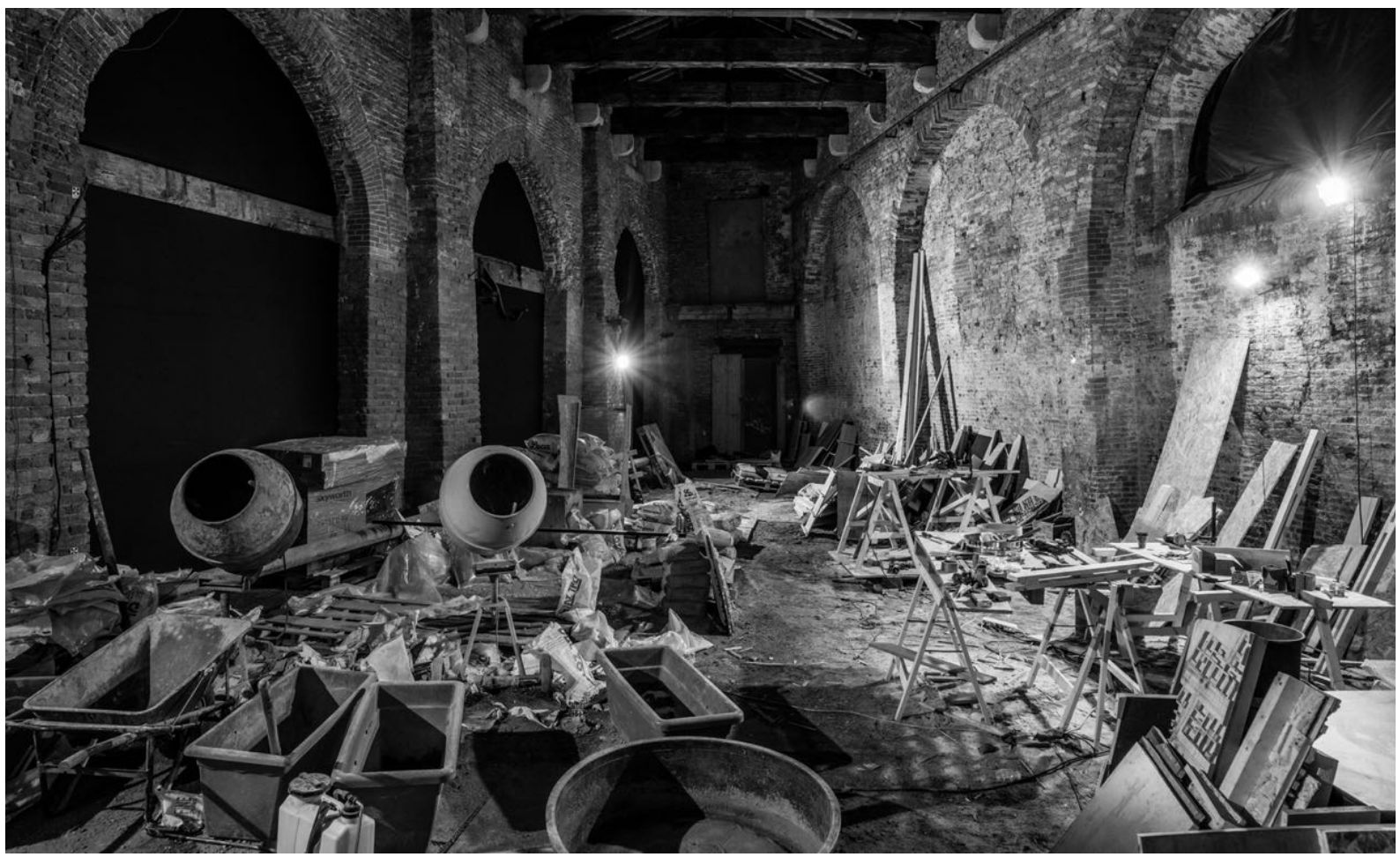


Fig. 07

Ciudad de Arlés. de la democracia en 1973, cuando se convirtió en centro de detención, régimen. Luego de 17 años de dictadura, el retorno a la democracia se celebraría en el mismo edificio desplegando una bandera chilena a lo largo de la arena central. En su forma circular, los estadios y anfiteatros tienden a no comprometerse con el tejido urbano de la ciudad, sin embargo, a nivel simbólico se convierten en registro de procesos políticos, sociales y culturales: los estadios del Estadio son los estadios de la ciudad.

Una maqueta arquitectónica de vivienda convertida en monumento se instala al centro de una sala de exposiciones, que fuera antes arsenal de guerra, como parte de una historia urbana específica. Como tipología, la presencia del estadio en el centro de la sala representa sin embargo no sólo el Estadio Nacional de Chile, sino también el Coliseo Romano y todos los estadios del mundo. La obsesión de Aldo Rossi con el estadio de Domiciano, el de Arles o el de Nimes se centra en su capacidad para contener la 'huella's de eventos del pasado. A través de ellos, la historia se convierte en una especie de marco compuesto por los artefactos de la ciudad. Estos ejemplos muestran cómo un tipo de edificio, de forma y función radical, es transformado y absorbido por el tejido urbano. Arles se transforma en ciudadela y Nimes en calles y lugares, mientras otros son totalmente absorbidos. A veces permanece la estructura, otras veces sólo la forma, pero siempre queda algo de la memoria preexistente. El proyecto del Papa Sixto V en 1590 para la transformación del Coliseo en una fábrica de algodón expone la esencia del problema de la forma del anfiteatro. El diseño contemplaba labo-

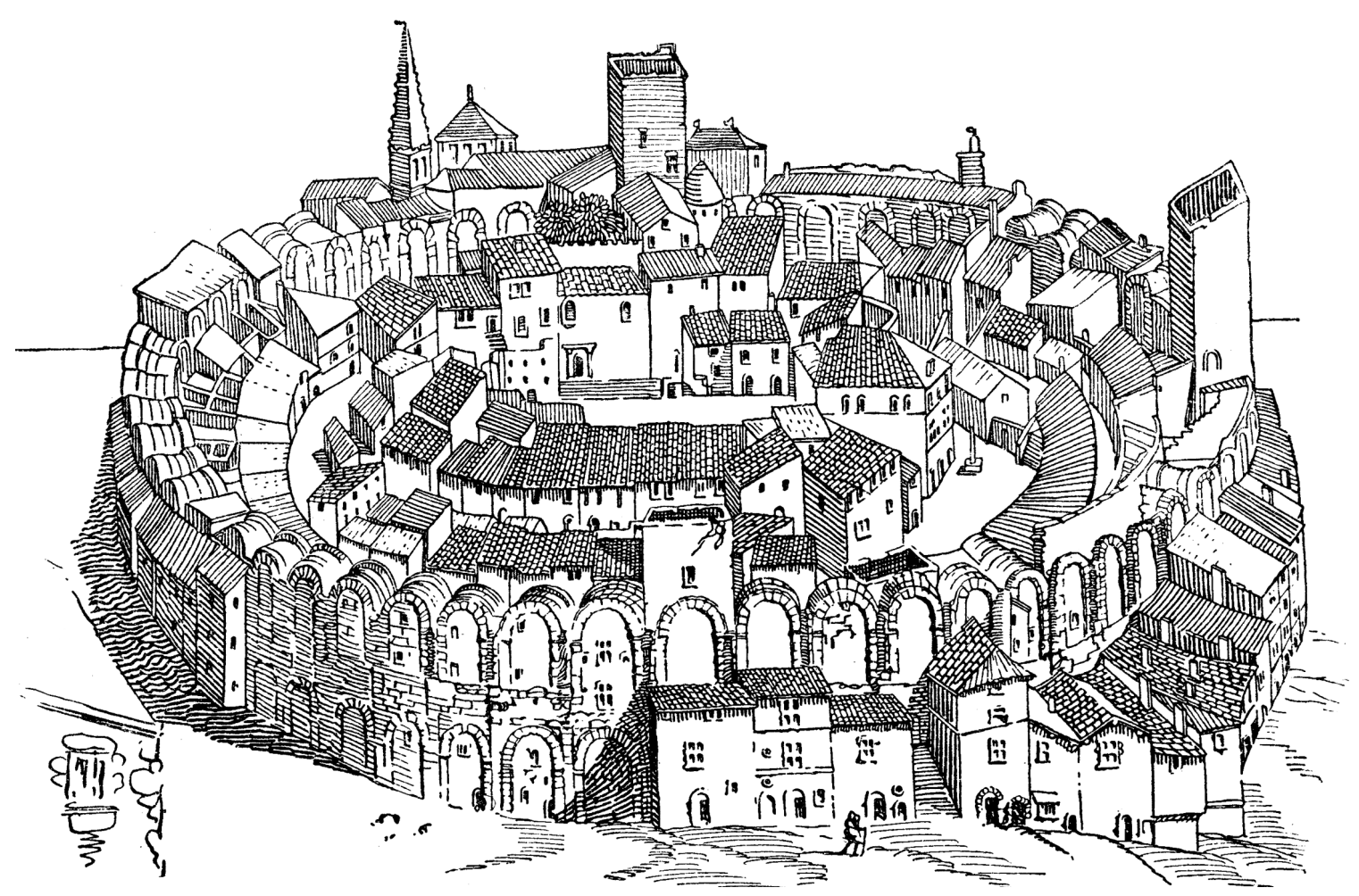

07 
ratorios en el primer piso y viviendas para trabajadores en los niveles superiores. Si el Papa hubiera vivido un año más, estas transformaciones habrían comenzado y el Coliseo habría sido efectivamente reducido a vivienda. La exposición logra combinar las 'permanencias' de Rossi en un solo gesto: viviendas y monumentos. El poder del 'tipo' para remitir a su origen se hace visible en "Stadium". Tal disolución o colapso de escalas permite comparar la planta urbana con la estructura general de sus partes: un artefacto colectivo que explica la metáfora de Rossi de la ciudad como una gran casa hecha por el hombre, un macrocosmos de la casa individual, desarrollando la frase de Alberti "la ciudad es como una gran casa y la casa, a su vez, como una ciudad pequeña" (fig. 07).

Cuestionando el estadio como tipología, la exposición es a la vez una investigación sobre la ciudad. El grabado de Piranesi Forma Urbis Romae fue una pieza clave para la propuesta curatorial "Stadium", tanto en términos de la recomposición de un sitio arqueológico como de un signo de la crisis de sentido de las partes en relación con un total. La imagen que nos devuelve la planta del Estadio Nacional no es sólo la de una ciudad invisibilizada, que se vuelve de repente demasiado prominente cuando se la comprime de manera análoga dentro de las formas del edificio, sino también la de una cuidad compuesta por islas, un archipiélago de poblaciones y villas carentes de un proyecto de la ciudad (fig. 08). Piranesi también realiza entre 1760 y 1778 una vista del coliseo en aguafuerte, conservada bajo el título de Veduta dell'Anfiteatro Flavio. Lo que el monumento significa para la ciudad de Roma se entrevé en la predicción del historiador Beda: "Mientras siga en pie el Coliseo, seguirá en pie Roma. Cuando caiga el Coliseo, caerá Roma. Cuando caiga Roma, caerá el mundo"6. Dicha capacidad indéxica del Coliseo Romano persiste en el Estadio de Chile, en la medida en que el edificio representa la totalidad la ciudad. Siguiendo las instrucciones de la planta y el fascículo, la superposición del edificio con la ciudad circundante se materializa en un código estético. En orden alfabético, como tantas otras listas biopolíticas propias de la modernidad (listas de víctimas o de convocados a la milicia), el fascículo separa las comunas y luego las villas y poblaciones, dándoles un sector y una puerta de acceso específicos ese día al estadio. A, BB, C, HH no sólo referencian las entradas al edificio, sino las puertas a través de las cuales la ciudad se transporta al edificio, lo que transforma a los residentes en propietarios y transfiere el problema de la vivienda de un servicio social a un bien de consumo. El estadio se transforma en un dispositivo para la administración de los cuerpos ese día en el edificio, pero también para el gobierno a largo plazo de los hombres en la ciudad. Estos programas coincidieron con la campaña del régimen para erradicar la pobreza extrema, directamente vinculada a reforzar su legitimidad. Dichos programas de vivienda pretendían no sólo dar paso al desarrollo privado de la totalidad de la producción de vivienda, sino también asegurar la lealtad al régimen: la lealtad a la hipoteca, la fidelidad de hombres y mujeres endeudados.

La retórica circular de la tipología del estadio se vuelve al mismo tiempo metáfora y aparato en su voluntad de limitar la ciudad y organizarla. La geometría ovalada garantiza la ficción de que el conocimiento y el reconocimiento son posibles dentro de esta muestra de un mundo totalmente controlado. La perfección geométrica aparece entonces como una nueva naturaleza para la construcción de otra subjetividad: la ilusión de un mundo comprimido en un interior, de espacios y 


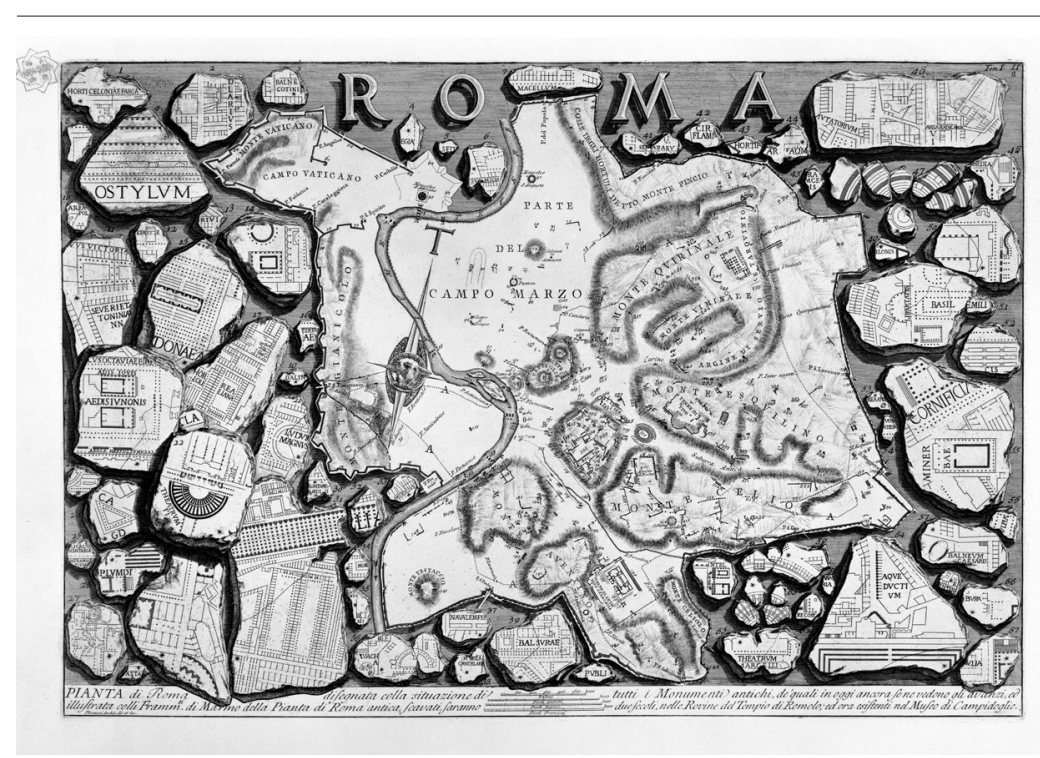

08

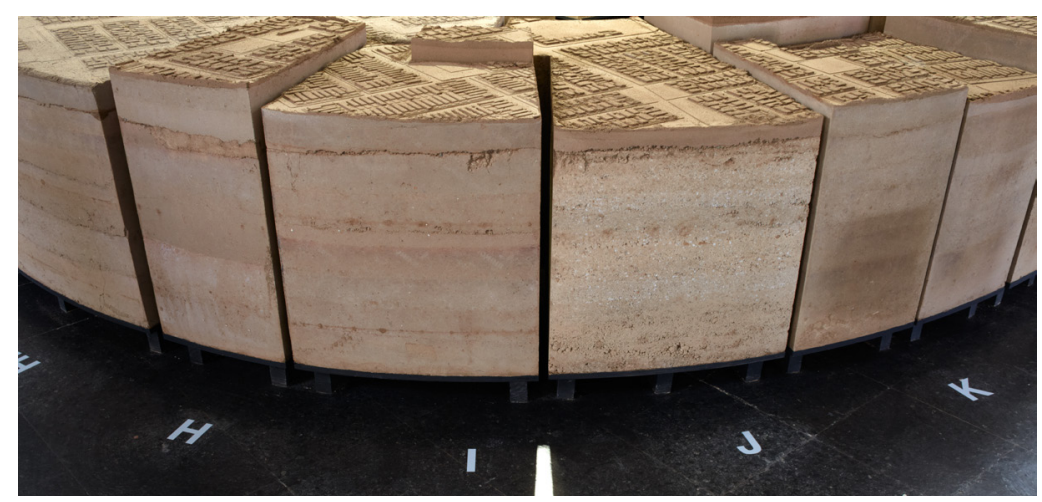

09

cuerpos susceptibles de ser organizados en una serie de compartimientos discretos basados en el rigor técnico y geométrico del edificio. Esto es lo que Jeremy Bentham desarrolla en su modelo de vigilancia perfecta, o 'museo de la naturaleza humana', como Foucault describió el panóptico. En la segunda versión de la exposición y su adaptación al espacio simétrico y axial del Museo de Arte Contemporáneo, la insistencia en la forma autónoma y la geometría cerrada del estadio se hace aún más evidente que en Venecia. La posibilidad de capturar la imagen sinóptica del edificio desde el segundo nivel del museo refuerza este aspecto gracias a la doble altura del vestíbulo y su vacío central (fig. 09).

El estadio y el museo se encuentran ahora en la misma ciudad, lo que les permite medirse, escalarse y orientarse mutuamente. Fue Rossi quien reintrodujo la historia y la tipología como elementos centrales de la arquitectura, condiciones que permitirían a la arquitectura servir como "medida del tiempo, y al revés, ser medida con el tiempo"7. La palabra estadio en inglés deriva del griego stadion, cuyo origen literal es la medida de distancia de la primera prueba de los Juegos Olímpicos en Grecia. Desde los años 776 hasta 724 a.C., el stadion fue el único evento que tuvo lugar en los Juegos Olímpicos; considerado como el más im-
Fig. 08

Giovanni Battista Piranesi, planta de Roma basada en Forma Urbis Romae Fuente: Le Antichità Romane, 1756-1757, vol. 1.

Fig. 09

Estadio y Museo a la misma escala. Estadio en el Museo escala 1:40. Fuente: (c) Carmen Valdés. 
portante, gradualmente se convirtió en la última prueba, denominada 'el final del estadio': una distancia entre dos puntos equivalente a una octavo de milla romana, un poco más de 600 pies o alrededor de 183 metros. La muestra opera en tanto 'stadium' como una medida de tiempo y distancia: mide el presente de una ciudad con su propio pasado, mide el centro de una ciudad con su periferia (fig. 10).

"Stadium", en su segunda versión y adaptación, confirma la posibilidad de que la arquitectura 'para' el museo no sólo registre y celebre obras construidas a preservar y difundir, como lo haría una biblioteca con los libros, sino que contribuya a un debate crítico sobre las propias prácticas arquitectónicas. La muestra problematiza temas que ya Rossi en 1966 nos invitó a revisar: cuestiones sobre tipología, representación, historia y memoria. Pero más allá de eso, invita a examinar los lugares donde se produce conocimiento en arquitectura, confirmando al museo como uno de ellos. El estadio encarna una técnica (la de administrar cuerpos a través de puertas y corredores), un lenguaje (un código estético y gramático que conecta el edificio a la ciudad) y una práctica (una

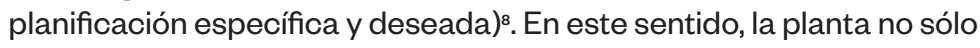
representa pasivamente el espacio delimitado y confinado del edificio, sino que se vuelve también inscripción activa de un proceso más amplio: geográfico y cartográfico, pero también histórico y narrativo.

Trasladar o dislocar un proyecto de investigación formal fuera de las aulas de la academia no sólo implica un registro y exposición de aspectos de la investigación a un público masivo, sino también construir un nuevo sitio epistemológico que coexiste con el proyecto. La arquitectura para los museos, siguiendo nuevamente a Rossi, sería el eje central de un discurso disciplinar con aspiraciones de relevancia cultural, que sólo posteriormente y en manos de técnicos, tomaría la forma de edificios. El museo abre un lugar diferente para la arquitectura: la posibilidad de un nuevo espacio de conocimiento con sus propias lógicas. RA

Fig. 10

Estadio y Museo a la misma escala. Estadio en el Museo escala 1:40. Fuente: (c) Carmen Valdés.

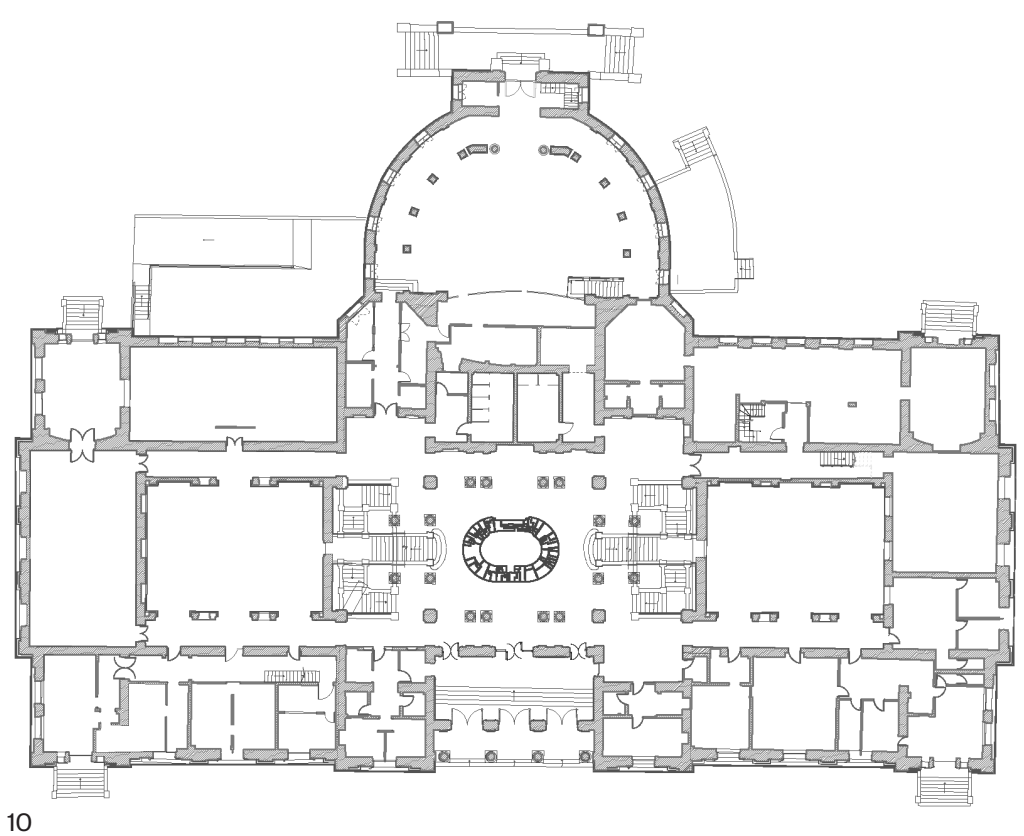




\section{Notas}

01. El autor agradece al Programa CONICYT Nº 79150067 "Economía política y retórica de la vivienda: estrategias arquitectónicas y políticas urbanas de vivienda en los años ochenta en Chile". Agradece asimismo a la Pontificia Universidad Católica de Chile por el apoyo brindado por la Vicerrectoría de Investigación Académica.

02. VIDLER, A., "Un edificio en un edificio". En: CELEDON, A., FELL, S., Stadium, Zurich, Park Books, 2018.

03. STACKHOUSE J., "The state of Housing, The Business of the State: The consequences of housing and urban development policies developed by the entrepreneurial state in Chile". Tesis para optar al grado académico de Doctor. Syracuse University, USA, 2007, p 170, p 298.

04. VIDLER, A., "Un edificio en un edificio", y ZAMBRA, A. "Propietario" En: CELEDON, A., FELL, S., Stadium, Zurich, Park Books, 2018.

05. ROSSI, A. The Architecture of the City, New York, Oppositions Books, 1982, p 5.

06. CANTER, H., (1930). The Venerable Bede and the Colosseum. Transactions and Proceedings of the American Philological Association, 61, 150-164. doi:10.2307/282798

07. ROSSI, A., The Architecture of the City, New York, Oppositions Books, 1982, p. 5.

08. LATHOURI, M., "Escribiendo la geografía intima de la ciudad". En: CELEDON, A., FELL, S., Stadium, Zurich, Park Books, 2018.

\section{Referencias Bibliográficas}

- ALBERTI, Leon Battista, De Rae Aedificatoria. On the Art of Building in Ten Books. Cambrige, Mass.: MIT Press, 1988.

- CANTER, Howard Vernon, "The Venerable Bede and the Colosseum". Transactions and Proceedings of the American Philological Association 61 (1930): 150-164.

- CELEDÓN, Alejandra, FELL, Stephannie (ed) "Stadium". Zurich: Park Books, 2018.

- CELEDÓN, Alejandra, (2018) "Un edificio que visualiza la imagen de una ciudad" En Anales de Arquitectura ed. Pedro Alonso, Pedro Correa. Santiago: Ediciones ARQ 2018.

- DE CASTRO, Sergio, et al. "El Ladrillo": Bases de la política económica del gobierno militar chileno. Santiago: Centro de Estudios Públicos, 1992.

- HOPKINS, Keith y BEARD, Mary, The Colosseum. Londres: Profile Books, 2011.

- Junta Militar. Mensaje Presidencial 11 de septiembre 1976 - 11 de septiembre 1977. Santiago: Servicio de Prisiones, 1977.

- Memoria 1979 Ministerio de Vivienda y Urbanismo. Santiago: Minvu, 1980.

- Ministerio Secretaría General de Gobierno. Jornadas del Presidente de la República. Visitas a las Regiones, 19781979, 1979.

- PIRANESI, Giovanni Battista, Le Antichità Romane. Vol. 1, Roma: Nella Stamperia Salomoni, 1784.

- ROSSI, Aldo, The Architecture of the City. Nueva York: Oppositions Books, 1982.

- "Arquitectura para los museos". In Para una arquitectura de tendencia: Escritos 1956-1972, 201-210. Barcelona: Gustavo Gilli, 1977.

-PURVES, Alex, Space and Time in Ancient Greek Narrative, Cambridge MA: Cambridge University Press, 200.

-STACKHOUSE, Jill, "The state of Housing, the business of the state: The consequences of housing and urban development policies developed by the entrepreneurial state in Chile (1973-1989)". Syracuse University, 2007.

- TAFURI, Manfredo, The Sphere and The Labyrinth: avant-gardes and architecture from Piranesi to the 1970s, Cambridge MA: The MIT Press, 1990.
- VIDLER, Anthony, "Un edificio en un edificio". In Stadium. Un edificio que visualiza la imagen de una ciudad, editado por Alejandra Celedón y Stephanie Fell, 12-17. Zurich: Park Books, 2018.

-ZAMBRA, Alejandro, "Propietario". In Stadium. Un edificio que visualiza la imagen de una ciudad, editado por Alejandra Celedón y Stephanie Fell, 48-53. Zurich: Park Books, 2018.
RA. Revista de Arquitectura Núm. 21 - 2019

P. $38-49$ 